\title{
BODY IMAGE AND MENTAL REPRESENTATION IN TABLE TENNIS PLAYERS WHO DO VERSUS DO NOT USE A PROSTHESIS
}

\author{
Damian Jeraj, Lisa Musculus, Babett H. Lobinger \\ German Sport University Cologne, Germany \\ E-mail: damianjeraj@gmx.de, I.musculus@dshs-koeln.de, lobinger@dshs-koeln.de
}

\begin{abstract}
The prosthesis that athletes use should take over the function of the missing limb. Playing table tennis without constraints is one exemplary goal. The question arose whether table tennis players who used a prosthesis and players who did not show similar body image values and mental representation of movements. Five matched pairs of active table tennis players $(n=10)$ completed a body image questionnaire. Additionally, the mental representation of a forehand table tennis serve was assessed. Results revealed no significant differences between the two groups of athletes on mental representations. Furthermore, the integration of the prosthesis into the body image was considered satisfying by four out of the five athletes with prosthesis, the use of a prosthesis did not appear to affect athletes'body image. Based on the research results it can be recommended that in technical and mental training sessions, one methodological approach be used for all athletes, regardless of whether they use a prosthesis. Finally, it is suggested to foster the integration of athletes who use a prosthesis into the established leagues in which athletes compete who do not use prosthesis.
\end{abstract}

Key words: functional body image, mental structure, SDA-M, athletes with disabilities.

\section{Introduction}

The construct of body image consists of functional and aesthetic dimensions, on both cognitive and affective levels. The goal of the present research was to further understand the link between body image, especially its functional dimensions, and the mental representation of movement, which also reflects the function of the investigated movement. The question arose whether the two functional related measures mentioned are influenced by the usage of a prosthesis.

Body image is seen as a multidimensional construct that is built by several perceptions of the individual's body (Brown, Cash, \& Milulka, 1990; Cash, Melnyk, \& Hrabosky, 2004; Cash, Thériault, \& Annis, 2004). Body image has been used as a measure in a variety of interventions, such as the treatment of eating disorders (Grabe, Ward, \& Hyde, 2008), and in comparisons of athletes and nonathletes (Hausenblas \& Downs, 2001). For instance, athletes showed higher values on the functional dimensions of body image than nonathletes (Abbott \& Barber, 2011; Jaffe \& Lutter, 1995), though different patterns emerged among athletes for different activities (Varnes, et al., 2013). Abbott and Barber (2011) concluded that "perceiving the body as physically competent or being satisfied with the way one's body functions may be contingent on other additional factors [...] 
rather than purely on valuing and investing in the functional qualities of the body" (p. 338). For sports participants who have a disability, a prosthesis takes over some of these specific functions. Vol. 11, No. 1, 2017 The body of a person who uses a prosthesis has to work in the specific sports activities. Thus, the question arises whether and how strongly especially these functional aspects of a prosthesis affect such a person's body image.

The integration of a prosthesis into one's body image can depend on several aspects, such as the fixation method, the weight of the prosthesis, or the length of time the prosthesis has been used (Carlson, Alvarez, Wu, \& Verstraten, 2010). However, studies have shown that the body image was adapted when wearing or not wearing the prosthesis (Canzoneri, Marzolla, Amoresano, Verni, \& Serino, 2013) and that even tools have been integrated into the body image (Maravita, Spence, \& Driver, 2003). In the case of tools, it has been argued that familiarization and training with the tool are essential for the tool to be integrated into the body image (Aglioti, Smania, Manfredi, \& Berlucchi, 1996; Maravita \& Iriki, 2004; Maravita, Spence, Kennetta, \& Driver, 2002), requirements that can both be seen as being fulfilled by people who use a prosthesis. Thus, it would be interesting to explore whether and how strongly a prosthesis is seen as a part of the body. Furthermore, the integration of a tool into the body image, such as a table tennis racket in the present research, would be relevant for athletes with and without prosthesis use, as well.

This presumed integration of the prosthesis into the body image does not necessarily mean that an athlete who uses a prosthesis produces a similar mental representation of a complex movement to that of athletes who do not use a prosthesis. An analysis of the mental structures of participants with limb aplasia was feasible (Bläsing, Schack, \& Brugger, 2010). Participants were asked to sort verbal labels of body parts and activities according to a hierarchical splitting paradigm, the socalled structural dimensional analysis-motoric (SDA-M; see Schack, 2012). Results revealed that even absent body parts were represented within the different clusters. This suggests that in terms of mental representation, people might be unaffected by a missing body part and that a prosthesis can replace an absent body part and its functions in mental representations. Yet to our knowledge, the mental representation of a complex athletic movement, such as the table tennis serve used in the present research (Schütz, Klein-Soetebier, \& Schack, 2009), of athletes who use a prosthesis has not been investigated so far. The question arises whether the mental representation of a complex movement is unchanged by the use of a prosthesis because the absence of different body parts (i.e., forearm, shank) and their replacement by a particular prosthesis would affect different functional aspects of the investigated movement.

In the present research it is investigated whether athletes who use a prosthesis had a similar body image to that of athletes who did not use a prosthesis, especially in its functional dimensions. In addition, mental representation is used as an additional measure of a movement's function, assuming that the functional image would be similar to its mental representation (cf. Bläsing at al., 2010). This exploratory research extends previous research in two ways: First, the functional body image of people who use a prosthesis is investigated and how their prosthesis is integrated into their body image. Second, the mental representation of a complex movement as a supplemental functional point of view is explored. The combination of the two areas (body image and mental representation) has never been used before, although their functional relation is important. The interesting part of the present research is that with this explorative approach a comparison of two subsamples might be possible. This explorative approach is also the reason why a formulation of clear hypotheses is not possible.

\section{Methodology of Research}

\section{Background of Research}

The present research is based on an online questionnaire that was active for four weeks in summer 2016. The aim was to determine whether athletes who use a prosthesis differ in their body image and in their mental representation of a table tennis skill, as compared to athletes who do not use a prosthesis. 
Initially, $N=85$ male and female table tennis players completed an online questionnaire. Of this group, five male players self-reported using one or more prostheses. Five male players from the remaining 80 are selected to generate five matched pairs. According to the cognitive action architecture approach, the mental representation of a skill is stored in long-term memory as a result of the learning process (Schack, 2004; Tenenbaum \& Land, 2009). Thus, the pairs are matched based on age and the players' table tennis experience in years, their level of play (competition leagues), and their training time in hours per week (Table 1). Because of gender differences in body image, the focus was on male participants only (Smolak \& Murnen, 2008). The resulting sample consisted of $n=10$ participants.

\section{Table 1. Demographic Characteristics of the Matched-Pairs Sample.}

\begin{tabular}{cccccc}
\hline Player & $\begin{array}{c}\text { Age } \\
\text { (years) }\end{array}$ & $\begin{array}{c}\text { Player } \\
\text { experience } \\
\text { (years) }\end{array}$ & $\begin{array}{c}\text { Training time } \\
\text { (hours/week) }\end{array}$ & $\begin{array}{c}\text { Level of play } \\
\text { (competition } \\
\text { league) }\end{array}$ & Kind of prosthesis \\
\hline A1 & 58 & 6 & 2 & $9^{\text {th }}$ & Both shanks \\
A2 & 53 & 4 & 2 & $8^{\text {th }}$ & - \\
B1 & 29 & 17 & 9 & $9^{\text {th }}$ & Thigh, shank, both forearms \\
B2 & 29 & 16 & 9 & $7^{\text {th }}$ & - \\
C1 & 74 & 63 & 2 & $7^{\text {th }}$ & Thigh \\
C2 & 71 & 60 & 2 & - & - \\
D1 & 37 & 13 & 4 & $8^{\text {th }}$ & Thigh \\
D2 & 28 & 15 & 4 & $9^{\text {th }}$ & - \\
E1 & 26 & 1 & 2 & - & Thigh \\
E2 & 63 & 3 & 3 & $8^{\text {th }}$ & - \\
\hline
\end{tabular}

Note. Pairs were labeled A-E. All participants were male. The 7th division of the German Table Tennis League is more skilled than the 8th league.

\section{Instruments}

Online questionnaire. An online questionnaire is composed consisting of a demographic section that included questions about the possible use of prostheses, a body image section, and an SDA-M section. All three sections were created in and displayed by the software package SoSci (SoSci Survey, Munich, Germany), which is specifically designed for professional scientific surveys and commonly used in noncommercial institutions. All sections of the questionnaire were designed so that anonymity would be ensured.

Body image. This section consisted of 20 items addressing the functional perception of the participant's own body, for example (translated from German), "I am satisfied with my body's function because I am able to do everything I want to do." Each item was rated on a 6-point Likert scale ranging from 1 (I do not agree at all) to 6 (I agree completely). The multidimensional body image section had a four-factor representation with an overall Cronbach's alpha coefficient of $\alpha=$ .84 (Musculus, Vogel, Kraus, \& Lobinger, 2016): (a) functional-affective body image, (b) aestheticaffective body image, (c) functional-cognitive body image, and (d) aesthetic-cognitive body image. One addition item asked how integrated into the participant's body image the prosthesis and the table tennis racket were. This item was rated on a 10-point Likert scale ranging from 1 (not at all) to 10 (completely). A second additional item asked the participants whether they saw the prosthesis and the table tennis racket as a part of their body. Both additional questions were chosen to assess the amount of integration of the prosthesis into the body image. 
SDA-M. The SDA-M instrument was used to assess the mental representation of a forehand Vol. 11, No. 1, 2017

backswing serve. The version used in the present research consisted of 13 text items (Schütz, Klein-Soetebier, \& Schack, 2009). Each item was paired with every other item, resulting in a 13 $\times 12$ matrix (156 decisions). Participants were asked to decide for each pair if the two displayed items were functionally related together or not (Schack, 2012). The items were (1) legs a little more than shoulder width apart, (2) toss ball to head height, (3) shift center of mass backward, (4) move racket backward, (5) rotate hip and shoulder to the right (left), (6) lay the wrist back, (7) focus on the ball, (8) lower body toward the point of ball contact, (9) rotate hip and shoulder into the ball, (10) move racket downward and forward, (11) open racket, (12) chopping motion of the wrist, and (13) sweep racket through.

\section{Procedure}

Participants completed the online questionnaire by using a link that was distributed through the national table tennis organization and the national disabled sports organization. They were informed on the first page of the questionnaire that they could cancel their participation without any consequences and that the data collection was completely anonymous. The aim of the research was presented together with an opt-in button where participants had to give their consent before completing the questionnaire. After providing consent, the participants filled out a demographic data sheet and an optional prostheses section, followed by the SDA-M section. Finally, all participants were asked to complete the body image section. In sum, they needed about 17 minutes to fill out the complete questionnaire. Before the start of the research, the university ethics committee approved the research design.

\section{Data Analysis}

For all calculations, a significance criterion of $\alpha=.05$ was defined. For body image, the mean of the four factors' data was analyzed in a descriptive way. In addition, a Mann-Whitney $U$ test was calculated to test for differences in athletes who did and did not use prostheses, as well as the corresponding Pearson correlation coefficient $r$ for a measure of the effect size. To analyze the SDA-M, several steps were necessary, starting with a hierarchical splitting procedure for each case, which resulted in the calculation of normalized $Z$ matrices (for details, see Schack, 2012). The following distance calculations of the SDA-M used the mental representation of the matched pairs: (a) The Adjusted Rand Index (ARI) was used as a measure of similarity (Rand, 1971; Santos \& Embrechts, 2009), which resulted in an index ranging from -1 (not similar) to 1 (same), and (b) the $\lambda$ value was used as a measure of invariance. Whereas the critical value of a cluster fusion resulted in $d_{\text {crit }}=$ 3.434 (Lander, 2002; Schack, 2012), the calculated range of the $\lambda$ value was between 0 and 1 , where a comparison of two mental representations were seen as invariant when $\lambda \geq .683$ and variant when $\lambda<.683$ (Lander \& Huth, 1999). Finally, (c) a descriptive analysis for each case was used. Data were analyzed using SPSS 24 and R 3.4.0 software.

\section{Results of Research}

Four of the five participants who used a prosthesis self-reported that they saw their prosthesis as part of their body image, and all five self-reported that the table tennis racket was not integrated into their body image. A Mann-Whitney $U$ test was used to look for a difference in athletes who did and did not use a prosthesis in the four factors of the body image. None of the calculations revealed a significant test value for the functional-affective body image: $U=11.00, Z=-.314, p=.841, r=.10$, the aesthetic-affective body image: $U=9.50, Z=-.649, p=.548, r=.21$, the functional-cognitive body image: $U=10.00, Z=-.530, p=.690, r=.17$, or the aesthetic-cognitive body image: $U=$ $12.50, Z=.000, p=.999, r=.00$. Thus, there was no difference between the two groups of athletes (see Figure 1). All participants, independent of whether they wore a prosthesis, agreed more with functional aspects than aesthetic aspects of the body, at least on a descriptive level. 


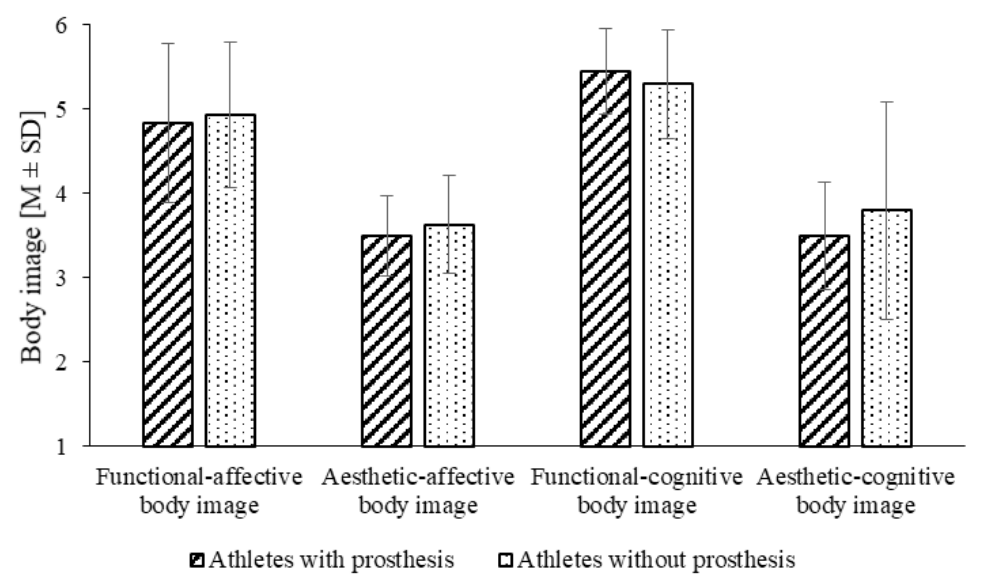
Figure 1: Means and standard deviations of the four factors of the body image
for the two groups of participants.

The calculations (ARI and $\lambda$ values) and the resulting tree diagrams of the distance measures of each mental representation of the matched pairs are shown in Figure 2. According to the similarity measure, all five matched pairs were seen as similar: all ARI values were .909 or higher. According to the invariance measure, three matched pairs (B1-B2; C1-C2; D1-D2) were invariant $(\lambda \geq .683)$, whereas the remaining two $(\mathrm{A} 1-\mathrm{A} 2$; E1-E2) were variant $(\lambda<.683)$. A descriptive analysis of the content of the items did not reveal a systematic difference among the five pairs. The number of clusters was almost identical for all pairs, although the content of the clusters was slightly different for the members of each matched pair.
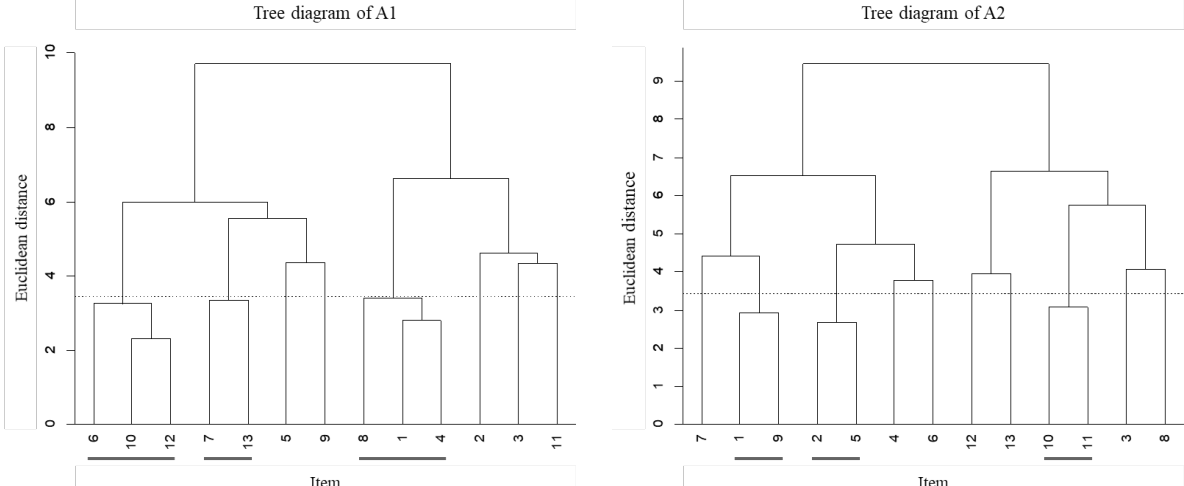

ARI: .932
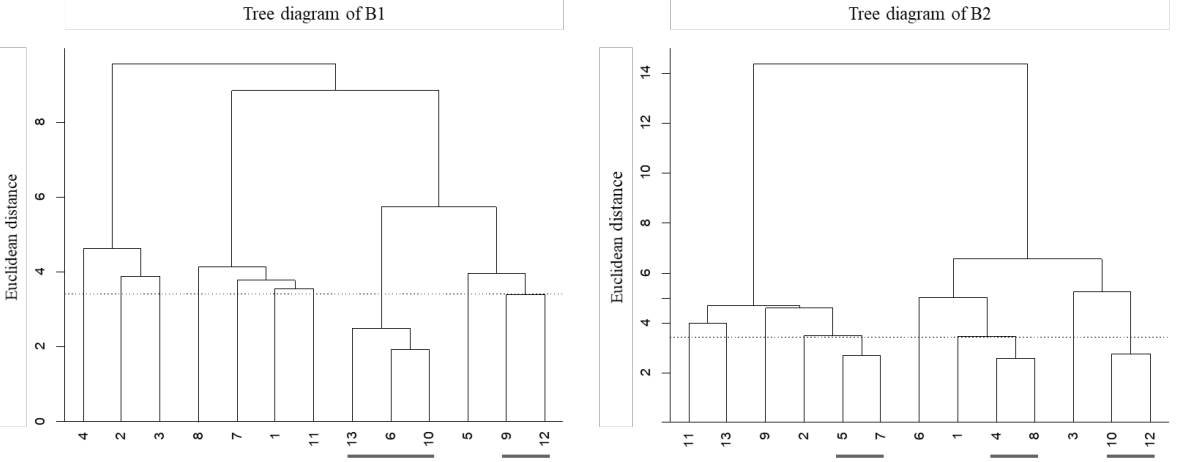

ARI: .953

$\lambda: .865^{\star}$ 

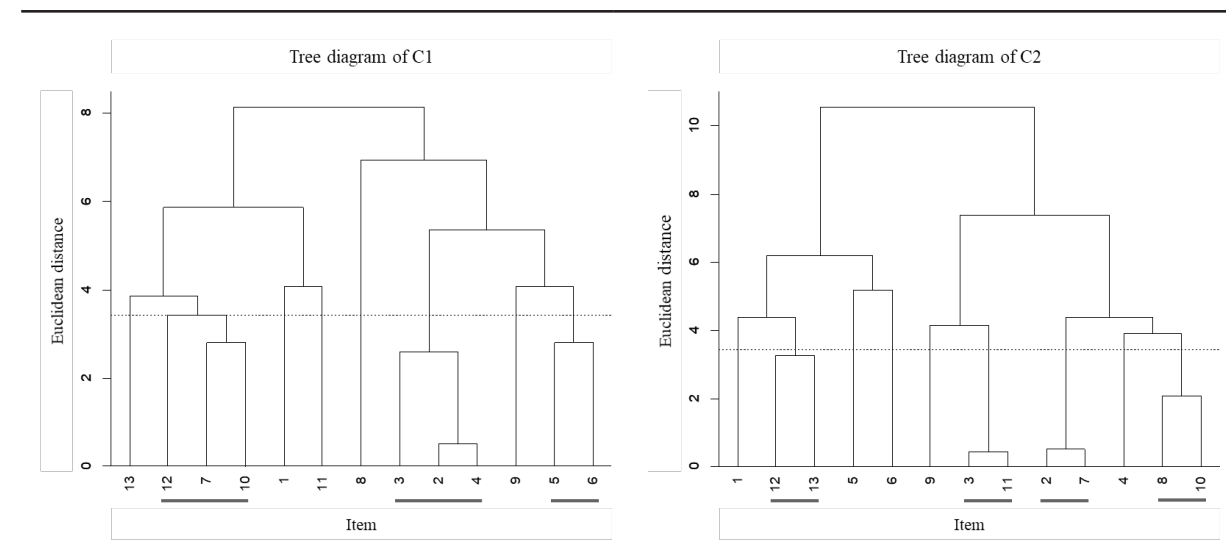

ARI: .924
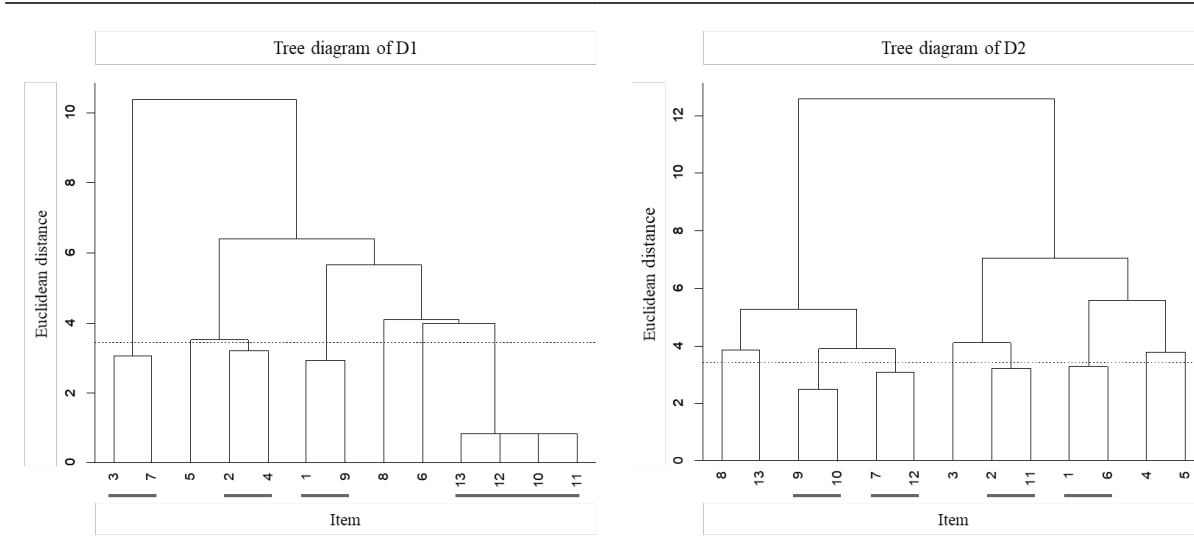

ARI: .909

$\lambda: .686^{*}$
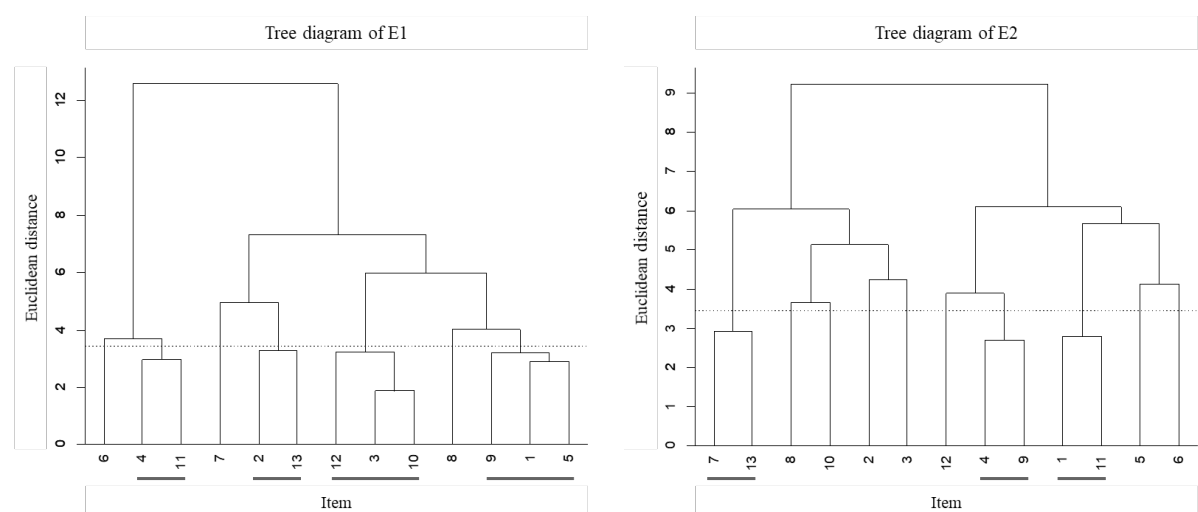

ARI: .924

A: .617

\section{Figure 2: $\quad$ Tree diagrams with calculated distance values of each matched pair of athletes.}

The dotted lines represent the critical $d$ value of 3.434 defined by structural dimensional analysis-motoric calculation. The item number refers to the number of the item described in the Materials section; clustering is identified by underlining the involved item numbers. The Adjusted Rand Index (ARI) value represents the similarity of two mental structures (higher values = more similar). The $\lambda$ value represents the invariance value of two mental structures; invariant values above the critical value of $\lambda=$ .683 are indicated by an asterisk.

\section{Discussion}

The present research investigated whether athletes who use a prosthesis perceived their body image similarly to athletes who do not use a prosthesis and whether they showed similar mental structures of a complex movement. Therefore, the body images and mental structures of the two samples using matched pairs are compared. 
There are no differences found in the body image reported by athletes who used a prosthesis and those who did not, in either its functional or aesthetic dimensions. The use of a prosthesis seemed to have no influence on the resulting body image, as four of the five table tennis players who used a prosthesis self-reported that the prosthesis was part of their body image. This was also independent of the type of prosthesis. This suggests that the prosthesis had taken over the function of the missing limb in a perfect manner. Although different sports lead to different body image patterns, in general, athletes tend to rate the functional dimensions of body image higher compared to nonathletes (Abbott \& Barber, 2011; Jaffe \& Lutter, 1995; Varnes, et al., 2013). These functional dimensions were similar in the present sample, as well; the use of a prosthesis did not appear to affect athletes' body image. In the light of studies comparing athletes and non-athletes (Abbott \& Barber, 2011; Jaffe \& Lutter, 1995; Varnes et al., 2013) the results obtained allow concluding that sports, whether or not people use a prosthesis, promotes a functional body image. Future research could also examine whether sports might even serve as a protective factor. In particular in the sense that when people who use a prothesis keep doing or even start doing sports, they might be less affected by negative changes in their aesthetic or functional body image. This intepretation is in line with studies showing that, due to familarization and training, even tools can be integrated into the body image (Maravita et al., 2003). Thus, sports can be considered as a suitable context for promoting the integration of prostheses.

There are no differences found in participants' mental representation of the investigated table tennis serve according to the similarity measure. The slight difference found in the invariance measure might have been caused by those participants who are less experienced with table tennis, this is also assumed by the grounded theoretical framework of building mental representations (Tenenbaum \& Land, 2009). Although one could recognize slight differences in the descriptive analysis in the tree diagrams of the matched pairs, no systematic difference emerged. This complements the body image findings and strengthens the assumption that athletes integrated their prosthesis into their body image. It also shows that slight individual differences occur which have to be analyzed in detail for further deductions, such as specific training programs as, for example, used in other sports for athletes who do not use a prosthesis (for an overview see Hennig, Velentzas, \& Jeraj, 2016).

Three specific limitations of the present research deserve mention: First, the sample consisted of five matched pairs, but as there are fewer table tennis athletes who use a prosthesis than those who do not (Dehghansai, Lemez, Wattie, \& Baker, 2017), one can assume that the sample is representative enough. Second, according to the cognitive action architecture approach (Schack, 2004), one can argue that the investigated mental structures were not identical compared to those an expert would produce. In comparison to Schütz and colleagues' (2009) results, the present tree diagrams exhibited more variation and less structured clusters. Reinvestigating the research question with athletes at the international competition level, who generally have a clearer representation, would clarify whether one can compare mental structures of athletes who do and do not use a prosthesis within one research. Third, one could discuss whether the results obtained with a very specific table tennis skill, can be transferred to other table tennis skills or other sport movements. As the present results in the two measures (body image and mental representation) seem to be systematic and go hand in hand, a transfer to other skills and sport movements is promising. Taken former and present research of mental representation into account that was conducted in other sports and other movements with athletes who do not use a prosthesis (Hennig et al., 2016), the results are stable here as well. However, one has to consider that the present results and the theoretical framework they are based on suppose that all functional aspects of the prosthesis are covered.

\section{Conclusions}

Given the similarities of the functional body images and mental structures reported here by athletes who do and do not use a prosthesis, one could deduce the necessity of matching methodological approaches in daily training to athletes using prostheses. Regardless of whether they use a prosthesis, athletes can be trained with the same methodological approaches. Therefore, further education for coaches who supervise athletes who use a prosthesis, as the social inclusion movement in Germany has requested, is not necessary. Furthermore, one could question whether the differentiation in the degree of handicap is still meaningful for the level of play, given that the functional aspects of the use of a prosthesis are ensured. Also, one could think about integrating athletes who use a prosthesis into 
Damian JERAJ, Lisa MUSCULUS, Babett H. LOBINGER. Body image and mental representation in table tennis players who do versus do not use a prosthesis

the established leagues in which athletes compete who do not use prosthesis, as is already done in some regions. Finally, in regard to the interindividual characteristics found in the present sample, it might be beneficial when analyzing data to do so not only on the group level but also on the individual level, especially when developing training recommendations and supporting the individual development of athletes.

\section{Acknowledgements}

The authors want to thank all members of the Department of Performance Psychology of the Institute for their critical feedback and Jannick Busch for his help in data collection. Also, the authors would like to thank all their participants.

\section{References}

Abbott, B. D., \& Barber, B. L. (2011). Differences in functional and aesthetic body image between sedentary girls and girls involved in sports and physical activity: Does sport type make a difference? Psychology of Sport and Exercise, 12, 333-342.

Aglioti, S., Smania, N., Manfredi, M., \& Berlucchi, G. (1996). Disownership of left hand and objects related to it in a patient with right brain damage. Neuroreport, 8, 293-296.

Bläsing, B., Schack, T., \& Brugger, P. (2010). The functional architecture of the human body: Assessing body representation by sorting body parts and activities. Experimental Brain Research, 203, 119-129.

Brown, T. A., Cash, T. F., \& Milulka, P. J. (1990). Attitudinal body-image assessment: Factor analysis of the Body-Self Relations Questionnaire. Journal of Personality Assessment, 55, 135-144.

Canzoneri, E., Marzolla, M., Amoresano, A., Verni, G., \& Serino, A. (2013). Amputation and prosthesis implantation shape body and peripersonal space representations. Scientific Reports, 3, 2844.

Carlson, T. A., Alvarez, G., Wu, D.-A., \& Verstraten, F. A. (2010). Rapid assimilation of external objects into the body schema. Psychological Science, 21, 1000-1005.

Cash, T. F., Melnyk, S. E., \& Hrabosky, J. I. (2004). The assessment of body image investment: An extensive revision of the appearance schemas inventory. International Journal of Eating Disorders, 35, 305-316.

Cash, T. F., Thériault, J., \& Annis, N. M. (2004). Body image in an interpersonal context: Adult attachment, fear of intimacy and social anxiety. Journal of Social and Clinical Psychology, 23, 89-103.

Dehghansai, N., Lemez, S., Wattie, N., \& Baker, J. (2017). A systematic review of influences on development of athletes with disabilities. Adapted Physical Activity Quarterly, 34(1), 72-90.

Grabe, S., Ward, L. M., \& Hyde, J. S. (2008). The role of the media in body image concerns among women: A meta-analysis of experimental and correlational studies. Psychological Bulletin, 134, 460-476.

Hausenblas, H. A., \& Downs, D. S. (2001). Comparison of body image between athletes and nonathletes: A meta-analytic review. Journal of Applied Sport Psychology, 13, 323-339.

Hennig, L., Velentzas, K. \& Jeraj, D. (2016). The Measurement of Mental Representations within the Context of Motor Actions. In T. Heinen, I. Čuk, R. Goebel, \& K. Velentzas (Hrsg.), Gymnastics Performance and Motor Learning - Principles and Applications (pp. 89-117). New York: Nova Science Publishers.

Jaffe, L., \& Lutter, J. M. (1995). Adolescent girls: Factors influencing low and high body image. Melpomene Journal, 14(2), 14-22.

Lander, H. J. (2002). Strukturdimensionale Analyse von Begriffssystemen [Structural dimensional analysis of item systems]. In T. Schack, T. Heinen, \& F. Engel (Eds.), Kognition und Bewegungssteuerung [cognition and motor control]. Cologne, Germany: MRI.

Lander, H. J., \& Huth, M. (1999). Ein Verfahren zur Ermittlung der Strukturierung und Dimensionierung begrifflich repräsentierten Wissens im Langzeitgedächtnis [An approach for the determination of structuring and dimensioning of item represented knowledge in long-term memory]. In E. Witruk \& H. J. Lander (Eds.), Informationsverarbeitungsanalysen - Kognitionspsychologische und meßmethodische Beiträge [information processing analyses - cognition psychological and measure methodological contributions] (pp. 83-98). Leipzig, Germany: Leipzig University Press. 
Damian JERAJ, Lisa MUSCULUS, Babett H. LOBINGER. Body image and mental representation in table tennis players who do versus do PROBLEMS

Maravita, A., \& Iriki, A. (2004). Tools for the body (schema). Trends in Cognitive Science, 8, 79-86.

Maravita, A., Spence, C., \& Driver, J. (2003). Multisensory integration and the body schema: Close to hand and within reach. Current Biology, 13, R531-R539.

Maravita, A., Spence, C., Kennetta, S., \& Driver, J. (2002). Tool-use changes multimodal spatial interactions between vision and touch in normal humans. Cognition, 83, B25-B34.

Musculus, L., Vogel, A., Kraus, U., \& Lobinger, B. (2016). Hauptsache, der Körper funktioniert! Das funktionale Körperbild bei Leistungssportlern ästhetischer und nicht-ästhetischer Sportarten [The important thing is that the body functions! The functional body image of athletes from aesthetic and unaesthetic sport]. In B. Halberschmidt, D. Dreiskämper, T. Utesch, M. Tietjens, K. Staufenbiel, L. Schücker, . . . B. Strauß (Eds.), Spitzenleistungen und Sportpsychologie: Der Weg zu Olympia - 48. Jahrestagung der Arbeitsgemeinschaft für Sportpsychologie [Elite performance and sport psychology: the road to Olympia $-48^{\text {th }}$ annual meeting of the German Society for Sport Psychology] (p. 134). Münster.

Rand, W. M. (1971). Objective criteria for the evaluation of clustering methods. Journal of the American Statistical Association, 66, 846-850.

Santos, J. M., \& Embrechts, M. (2009). On the use of the Adjusted Rand Index as a metric for evaluating supervised classification. In C. Alippi, M. Polycarpou, C. Panayiotou, \& G. Ellinas (Eds.), Lecture Notes in Computer Science 5769: Artificial Neural Networks, ICANN 2009, Part 2 (pp. 175-184). Berlin, Germany: Springer.

Schack, T. (2004). The cognitive architecture of complex movement. International Journal of Sport and Exercise Psychology, 2, 403-438.

Schack, T. (2012). Measuring mental representations. In G. Tenenbaum, R. C. Eklund, \& A. Kamata (Eds.), Measurement in sport and exercise psychology (pp. 203-214). Champaign, IL: Human Kinetics.

Schütz, C., Klein-Soetebier, T., \& Schack, T. (2009). Modeling of biomechanical parameters based on LTM structures. In G. S. Helge Ritter (Ed.), Human centered robot systems: Cognition, interaction, technology (pp. 161-191). Berlin: Springer.

Smolak, L., \& Murnen, S. K. (2008). Drive for leanness: Assessment and relationship to gender, gender role and objectification. Body Image, 5, 251-260.

SoSci. (2015). SoSci Survey [Computer software]. Munich, Germany.

Tenenbaum, G., \& Land, W. M. (2009). Mental representations as an underlying mechanism for human performance. Progress in brain research, 174, 251-266.

Varnes, J. R., Stellefson, M. L., Janelle, C. M., Dorman, S. M., Dodd, V., \& Miller, M. D. (2013). A systematic review of studies comparing body image concerns among female college athletes and non-athletes, 1997-2012. Body Image, 10, 421-432.

Received: October 18, 2017

Accepted: December 20, 2017

Damian Jeraj Dr., Associate Researcher, German Sport University Cologne, Institute of Psychology, Am Sportpark Muengersdorf 6, 50933 Cologne, Germany.

E-mail: damianjeraj@gmx.de

Website: http://www.dshs-koeln.de/psychologie

Lisa Musculus Research assistant/PhD Student, German Sport University Cologne, Institute of Psychology, Am Sportpark Muengersdorf 6, 50933 Cologne, Germany.

E-mail: I.musculus@dshs-koeln.de

Website: http://www.dshs-koeln.de/psychologie 